\title{
Peningkatan Keterampilan Bahasa Inggris SMPN 19 Mataram Melalui Model Triple $\boldsymbol{P}$
}

\author{
Lela Rahmawati ${ }^{1}$, Sutarman ${ }^{2}$ \\ lelarahmawati133@gmail.com ${ }^{1}$, sutarman@universitasbumigora.ac.id ${ }^{2}$ \\ ${ }^{1,2}$ Universitas Bumigora
}

\begin{abstract}
Article History:
Received: 12-01-2021

Accepted: 28-01-2021
\end{abstract}

Keywords: English course, Students, Triple P media.

\begin{abstract}
SMPN 19 Mataram which is in the area of Jalan DR. Soedjono Lingkar Selatan No.14, Dasan Cermen, Sandubaya district, Mataram City, West Nusa Tenggara. Because the location of the school is included in the suburbs and the English language skills at the school are still low. Based on conditions above, the Teaching team are interested in conducting education service by providing English language course using Triple $P$ model for the students in SMPN 19 Mataram. This course used media Triple $P$ (Present, Practice, Production) method with the aim of making the course activities more interesting and easier for the course participants. This English coursing activity has positive impact for the students in SMPN 19 Mataram. These positive impacts seen through the result of the coursing process. Within a few months of following the coursing process by using Triple $P$ media, the learning outcomes of the training participants increased. Before participating in the coursing, the coursing participants considered English was a difficult language to learn, but after participating in the coursing by using Triple $P$ media the students began to experience convenience and the students thought that learning English using Triple $P$ media was fun.
\end{abstract}

\section{Pendahuluan}

Pengabdian kepada masyarakat merupakan salah satu dharma atau tugas pokok dari suatu perguruan tinggi, disamping dharma pengajaran, dharma penelitian serta dharma pengabdian pada masyarakat. Khusus untuk dharma pengabdian pada masyarakat, dosen di tuntut untuk melakukan kegiatan pengabdian kepada masyarakat dengan terjun secara langsung untuk menerapkan ilmu yang dimiliki kepada masyarakat khususnya pada daerah atau lokasi yang menjadi sasaran kegiatan pengabdian seperti yayasan, instansi atau desadesa terpencil yang masih kekurangan sumberdaya yang memadai.

Salah satu instansi yang saat ini dijadikan sebagai lokasi pengabdian adalah SMPN 19 Mataram yang berada di Jalan DR. Soedjono wilayah Lingkar Selatan No.14, Dasan Cermen, Kecamatan Sandubaya, Kota Mataram, Nusa Tenggara Barat. SMPN 19 Mataram didirikan pada tahun 2004, sekolah ini terletak di Jalan DR. Soedjono Lingkar Selatan Kelurahan Dasan Cermen Kecamatan Sandubaya Kota Mataram. Berdasarkan data tahun 2018 dalam proses pembelajaran SMPN 19 Mataram memiliki rasio siswa rombongan 
belajar 30:19, rasio siswa ruang kelas 37:15, rasio siswa guru 19:32, Presentase Guru kualifikasi 100\%, Presentase guru sertifikasi 52\%, presentase guru PNS 64\%, presentase ruang kelas layak $100 \%$.

Selain itu, SMPN 19 Mataram merupakan sekolah menengah pertama yang terletak di pinggiran kota dengan jumlah guru sebanyak 25 orang, siswa laki-laki 259, siswa perempuan 224, rombongan belajar 16. Dalam proses belajar kurikulum yang digunakan oleh SMPN 19 Mataram tersebut menggunakan kurikulum 2013 dan penyelenggaraan pembelajaran dilakukan selama 6 jam dari pukul 07.00 sampai dengan pukul 13.00. Di SMPN 19 Mataram, ujian tengah semester dan ujian akhir semester sudah menggunakan ujian berbasis komputer, sehingga membuat siswa siswi sudah terintegrasi dengan dunia digital dan memudahkan guru dalam melakukan penilaian. Hal tersebut dapat membuat siswa-siswi memiliki motivasi yang lebih tinggi untuk mempersiapkan ujian yang dilakukan dengan menggunakan komputer tidak menggunakan manual. Di sekolah ini, sudah dilengkapi dengan akses internet, daya listrik 5.500 watt, Luas tanah $5.280 \mathrm{~m}^{2}$. Selain itu, sekolah ini memiliki ruang kelas sebanyak 13 ruang, 2 laboratorium, 1 perpustakaan, dan 2 buah sanitasi siswa (SMPN 19 Mataram, 2018).

Berdasarkan hasil pengamatan, proses belajar mengajar siswa-siswi SMPN 19 Mataram disekolah sudah berjalan dengan baik, namun ada beberapa mata pelajaran yang harus ditingkatkan salah satu contohnya yaitu mata pelajaran bahasa inggris. Karena adanya pengaruh dari faktor lingkungan, waktu pelajaran yang sangat kurang, metode pembelajaran yang kurang tepat sasaran serta kurangnya motivasi dari siswasiswi SMPN 19 Mataram yang menyebabkan tidak tercapainya target pembelajaran dalam mata pelajaran bahasa inggris khususnya dalam keahlian berbicara bahasa inggris. Kemampuan menggunakan bahasa secara lisan (speaking), baik bahasa ibu maupun bahasa target, merupakan kegiatan pembiasaan. Hal ini dapat terlihat dari fakta yang ditemukan dalam kehidupan sehari-hari. Seseorang mampu menggunakan bahasa ibu dengan baik bukan melalui proses pembelajaran tetapi hanya melalui proses pemerolehan dan pembiasaan. Artinya secara otomatis tanpa disadari seseorang memperoleh pajanan dari lingkungan pengguna bahasa dan berdasarkan pajanan tersebut mereka membiasakan penggunaan bahasa yang mereka peroleh (acquire). Begitu juga proses pembelajaran yang seharusnya dapat dianalogikan sebagai seseorang yang baru lahir dan masih dalam rangka memperoleh bahasa ibu (pertama). Pembelajar bahasa seharusnya diberi banyak kesempatan dan peluang untuk membiasakan diri menggunakan bahasa tersebut, bukan mempelajari tentang bahasa itu (Wiratno, 2018). 
Salah satu model pembelajaran bahasa khususnya keterampilan speaking yang dapat memberikan peluang yang banyak kepada siswa untuk menggunakan bahasa adalah model Triple $P$. Dalam buku (Harmer, 2004) memperkenalkan model pembelajaran Triple $P$ dalam rangka meningkatkan kemampuan pembelajar bahasa memproduksi bahasa target. Metode Triple $P$ ini merupakan metode Audio - lingualism yang disempurnakan oleh (Harmer, 2004). Dari beberapa keterampilan bahasa target, keterampilan speaking merupakan keterampilan yang penting karena dalam kehidupan sehari-hari seseorang lebih banyak menghabiskan waktu untuk berbicara (komunikasi lisan) ketimbang komunikasi tulis. Di samping itu seseorang yang mampu mengungkapkan gagasannya dalam bahasa lisan dengan baik dengan sendirinya orang tersebut juga mampu mengungkapkan gagasan mereka dalam bahasa tulis. Selain itu, Richards \& Renandya, (2002) mengemukakan bahwa pembelajaran komponen bahasa berfungsi sebagai media atau alat untuk menguasai keterampilan berbicara dalam bahasa Inggris (speaking). Selain itu, bahasa digunakan untuk mengungkapkan realitas sosial dan berkenaan dengan interaksi antara penutur/penulis dan pendengar/pembaca. Dibawah fungsi tekstual, bahasa digunakan untuk mengungkapkan realitas semiotis atau realitas simbol dan berkenaan dengan cara penciptaan teks dalam konteks (Batemen, 1992).

Untuk itu muara dari mempelajari komponen bahasa Inggris (vocabulary, pronunciation dan grammar) adalah penguasaan keterampilan berbicara. Dengan demikian sangatlah beralasan untuk menerapkan metode triple $P$ dalam pembelajaran keterampilan bahasa dan komponen bahasa agar tujuan akhir pembelajaran tercapai yaitu kemampuan memproduksi bahasa. Fakta yang ditemukan dalam pelaksanaan pembelajaran speaking saat ini adalah pembelajar belum memiliki semangat yang optimal untuk menggunakan bahasa target dalam komunikasi sehari-hari baik dengan teman, dosen/guru dan dengan lingkungan. Bahkan beberapa diantara pembelajar merasa enggan untuk berbicara bahasa Inggris meskipun sudah diminta oleh pengajar (guru/ dosen). Pembelajar tersebut lebih cenderung menggunakan bahasa ibu dalam komunikasi di dalam kelas walaupun itu adalah kelas speaking. Hal ini merupakan kesenjangan yang ditemukan dalam pelaksanaan pembelajaran speaking. Sudah menjadi kewajiban bagi pengajar (dosen/guru) mencari model pembelajaran speaking yang proporsional untuk meningkatkan kreatifitas pembelajar dalam menggunakan bahasa target (bahasa inggris). Salah satu model yang dikemukakan oleh (Harmer, 2004) adalah model Triple $P$ untuk meningkatkan kreatifitas pembelajar menggunakan bahasa target (bahasa inggris).

Mengingat akan kondisi di atas dan keinginan untuk membantu pemerintah untuk mencerdaskan kehidupan bangsa melalui pendidikan, maka kami selaku dosen atau 
pengajar memandang perlu untuk memberikan kegiatan yang positif bagi siswa-siswi SMPN 19 Mataram kelas 9 dalam bentuk kursus bahasa Inggris yang bisa mengembangkan kemampuan dan keterampilan siswa-siswi SMPN 19 Mataram tersebut dengan harapan nantinya setelah mereka mengikuti kursus bahasa Inggris mereka akan memiliki keterampilan bahasa Inggris yang bisa digunakan untuk mencari pekerjaan dan melanjutkan pendidikan ke jenjang yang lebih tinggi.

\section{Metode}

Dalam pelaksanaan kursus bahasa Inggris bagi siswa-siswi SMPN 19 Mataram, sudah tentu dibutuhkan metode yang sifatnya bisa mempermudah dan membantu kegiatan kursus ini. Kursus ini menggunakan metode pelatihan dengan menggunakan Triple $P$ (Presentation, Practice dan Production) dengan tujuan agar kegiatan kursus lebih menarik dan mudah di pahami serta diperaktekkan oleh peserta pelatihan. Penerapan metode ini menggunakan strategi sebagai berikut:

1. Teori

Dalam pelatihan bahasa dibutuhkan dasar berupa teori. Teori ini terkait dengan gambaran umum tentang bahasa Ingris dan materi yang akan di bahas dalam praktik. Selain itu dalam teori dibahasa pula kiat-kiat sukses dalam belajar bahasa Inggris. Adapun pemberian teori ini berguna untuk menunjang kegiatan praktik.

2. Praktik

Untuk menunjang pelatihan bahasa Inggris dibutuhkan kegiatan pengalaman secara langsung yaitu berupa praktik. Praktik ini berupa pemutaran video dalam bahasa inggris yang berisi penggunaan bahasa Inggris dalam kegiatan sehari-hari. Setelah pemutaran materi berbasis audio visual, peserta diminta untuk mempraktikkan apa yang sudah didapat dari pelatihan dalam bentuk praktik berbicara.

3. Evaluasi

Evaluasi bertujuan untuk melihat seberapa efektif kegiatan yang telah dilakukan dan mengetahui kekurangan sehingga akan menjadi bahan masukan dan perbaikan pada kegiatan pengabdian masyarakat berikutnya. 


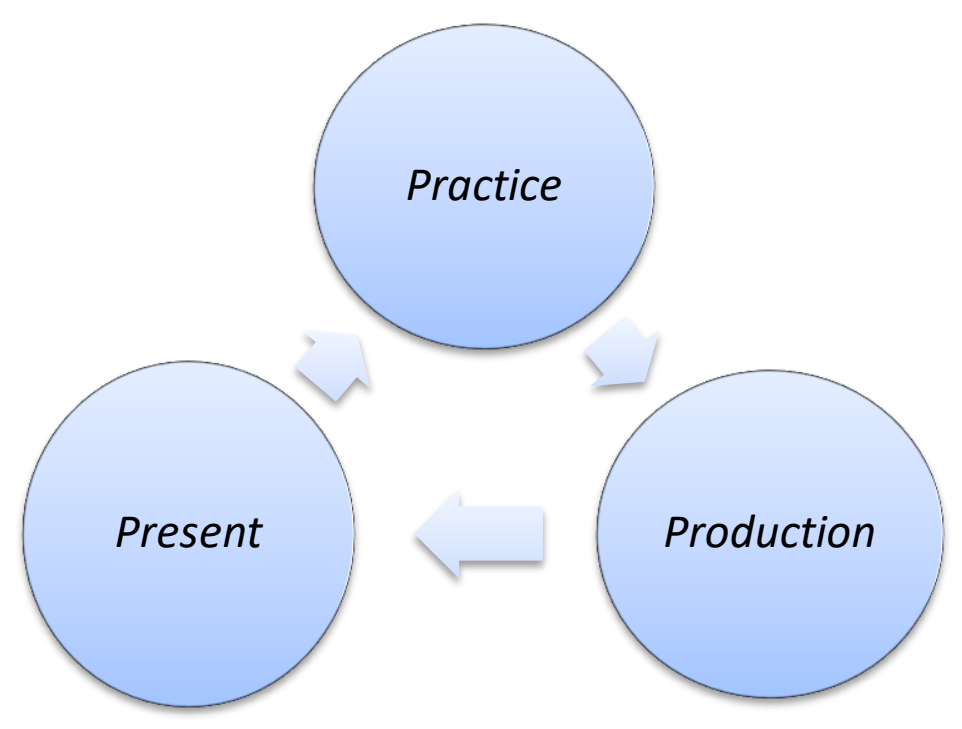

Gambar 1. Diagram metode pengabdian

\section{Pembahasan}

Langkah awal yang kami lakukan dalam kegiatan pengabdian masyarakat di SMPN 19 Mataram adalah dengan mengadakan survey dan pendekatan kepada siswa-siswi tersebut. Pendekatan dilakukan untuk mengetahui kondisi riil dari siswa-siswi tersebut. Kegiatan pendekatan ini dilakukan kurang lebih selama satu minggu. Adapun kegiatan pendekatan pertama yang dilakukan adalah mendatangi kepala Sekolah dan Guru yang bertanggung jawab atas kegiatan yang terkait dengan proses pembelajaran dengan tujuan selain untuk menyampaikan maksud dan tujuan dari kegiatan pengabdian juga untuk mendapatkan informasi terkait dengan kondisi siswa-siswi tersebut. Berdasarkan pendekatan dan informasi dari Kepala Sekolah dan Guru, terdapat total kurang lebih 30 siswa di setiap kelas. Kelas 9 terdiri dari 4 kelas, jadi total keseluruhan 120 siswa. Namun yang mengikuti kegiatan kursus bahasa Inggris ada 80 orang karena sebagian siswa sudah mengambil kelas kursus berbayar seperti Ganesha Operation dan tempat kursus lainnya. Dari 80 orang siswa- siswi tersebut sebagian besar adalah siswa-siswi yang kurang mampu sehingga mereka sangat senang dalam mengikuti kursus gratis yang diberikan oleh kami selaku dosen pengajar.

Untuk proses kegiatan kursus diadakan di Sekolah SMPN 19 mataram pada sore hari sekitar pukul 16.00. Adapun materi yang diberikan kepada peserta kursus adalah berupa materi dasar bahasa Inggris dan praktik langsung dalam bentuk percakapan. Materi disajikan dengan menggunakan media Triple P model (Presentation, Practice, Production) agar pembelajaran berlangsung dengan lebih menarik sehingga mereka termotivasi untuk tetap mengikuti pelatihan. Waktu pelatihan diadakan 2 (dua) kali dalam seminggu dengan 
waktu belajar sekitar 2 jam pada hari Sabtu dan Minggu.

Dalam beberapa bulan menjalani proses kursus dengan menggunakan Triple $P$. Menurut Harmer, (2004) metode/ model Triple $P$ merupakan modifikasi dari metode audio lingualism, dimana model ini bukan memberi fokus pada pengulangan bahasa lepas konteks akan tetapi Harmer, (2004) memberi fokus pada production berupa penggunaan bahasa target sesuai dengan konteks, Pembelajar bahasa (siswa) menggunakan bahasa melalui teknik reproduksi yang tepat. Disamping itu pembelajar juga dapat merespon pertanyaan dosen dengan menggunakan kata-kata, phrase, atau kalimat yang diajarkan. Dengan kata lain dapat dikatakan bahwa model triple $P$ ini mirip dengan metode audiolingual klasik namun untuk metode triple $P$, pengulangan kata-kata atau phrase lebih bermakna dan berdasarkan konteks. Pada akhirnya pembelajar, dengan menggunakan kata-kata atau phrase baru yang dipelajari, akan mampu merangkai katakata tersebut menjadi kalimat dalam berbicara (speaking) dan semua itu mengacu kepada kegiatan production. Implementasi model triple $P$ ini mengacu kepada tiga tahap utama yaitu tahap presentation, practice dan tahap production.

Pada tahap presentation pengajar memperkenalkan topik pembelajaran yang akan dipelajari sesuai dengan silabus yang sudah disusun. Kegiatan presentasi kadang kala dibantu oleh media baik berupa gambar atau media berbasis teknologi seperti menggunakan powerpoint. Hal yang perlu menjadi perhatian pada tahap presentasi adalah media yang digunakan harus sesuai dengan topik yang dipelajari. Disamping itu pengajar memperkenalkan kata-kata baru (vocabulary) yang berhubungan dengan topik.

Tahap yang kedua adalah tahap practice (praktik) maksudnya tahap ini merupakan tahap/ kegiatan untuk melatih keterampilan pembelajar/ mahasiswa menggunakan bahasa secara lisan (speaking). Latihan ini bertujuan untuk membentuk kebiasaan mahasiswa berbicara menggunakan bahasa inggris. Dengan latihan yang berulang-ulang akan dapat membentuk kebiasaan pembelajar. Latihan pengulangan dapat dilakukan berupa pengulangan (repetation), atau berupa respon/ tanggapan mahasiswa terhadap pertanyaan dosen. Contoh pertanyaan tersebut adalah "what do you do every morning, evening and every night? Namun latihan tertulis juga dapat dilakukan. Muara latihan tersebut adalah production.

Tahap yang terakhir dari metode triple $P$ adalah production dimana sebagian besar para ahli menamakan immediate creativity atau kreatifitas langsung. Pada tahap ini dosen akan menyarankan mahasiswa untuk melakukan bermacam-macam kegiatan seperti kegiatan main peran (role play), bercerita sesuatu yang berkaitan dengan topik, mendeskripsikan gambar, interview, game dan kegiatan yang bermakna lainnya sebagai wujud dari production (penggunaan bahasa) tentang suatu topik pembelajaran. Topik 
cerita yang akan diceritakan tentunya sangat berkaitan erat dengan materi pembelajaran yang dipelajari, sehingga materi pembelajaran yang dipelajari dapat diaplikasikan langsung dalam menyampaikan gagasan atau komunikasi secara lisan.

Menurut Rodgers et al., (1986) sejumlah besar pembelajar bahasa di dunia mempelajari bahasa untuk mengembangkan dan meningkatkan keterampilan pembelajar dalam berbicara (speaking) bahasa target khususnya bahasa Inggris. Dengan kata lain pembelajar bahasa Inggris ingin menjadikan dirinya mahir dalam menggunakan bahasa Inggris untuk berkomunikasi lisan agar mereka dapat berkomunikasi dengan siapa saja yang ada di belahan dunia karena bahasa Inggris digunakan di seluruh pelosok dunia

Dalam mengajar kursus bahasa Inggris dengan menggunakan Triple $P$ ini terlihat peningkatan hasil belajar peserta. Sebelum mengikuti pelatihan peserta kursus menganggap bahasa Inggris merupakan bahasa yang sulit untuk dipelajari namun setelah mengikuti kursus dengan menggunakan media Triple $P$ siswa-siswi SMPN 19 Mataram mulai mengalami kemudahan dan siswa-siswi menganggap bahwa belajar bahasa inggris dengan menggunakan Triple $\mathrm{P}$ terasa menyenangkan. Terlihat juga beberapa pemuda siswa-siswi sudah mulai menggunakan percakapan ringan ketika berinteraksi dengan sesama siswa, Guru dan teman lainnya.

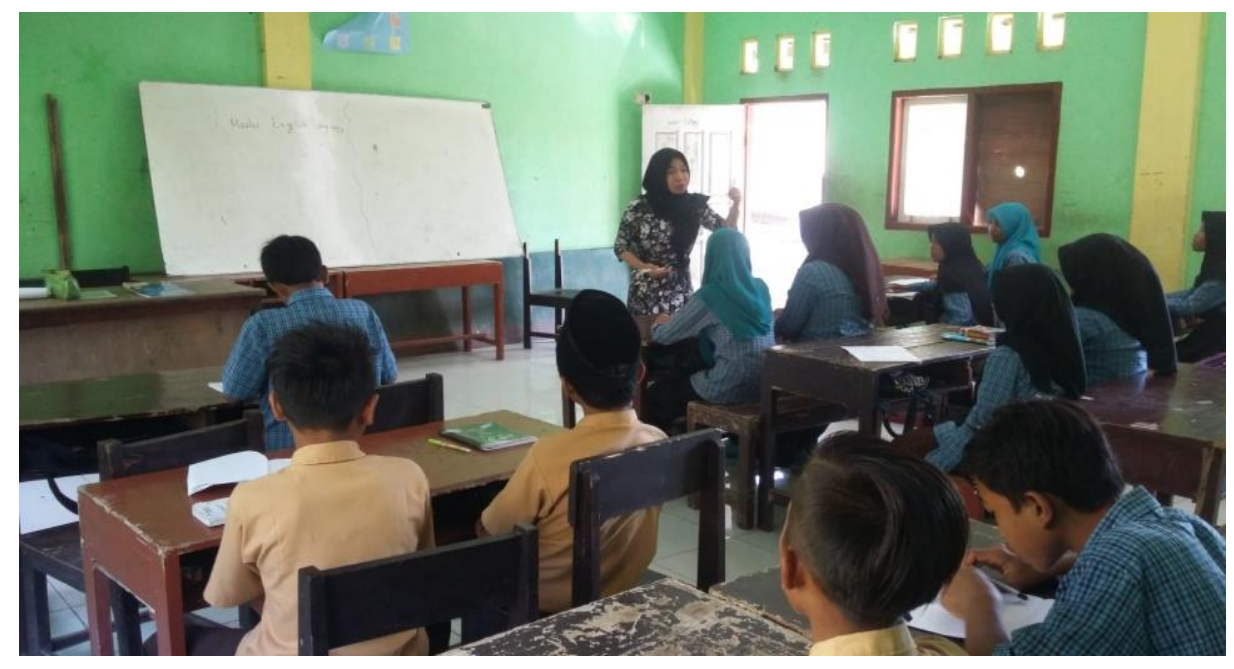

Gambar 2. Foto dokumentasi pengabdian 1 


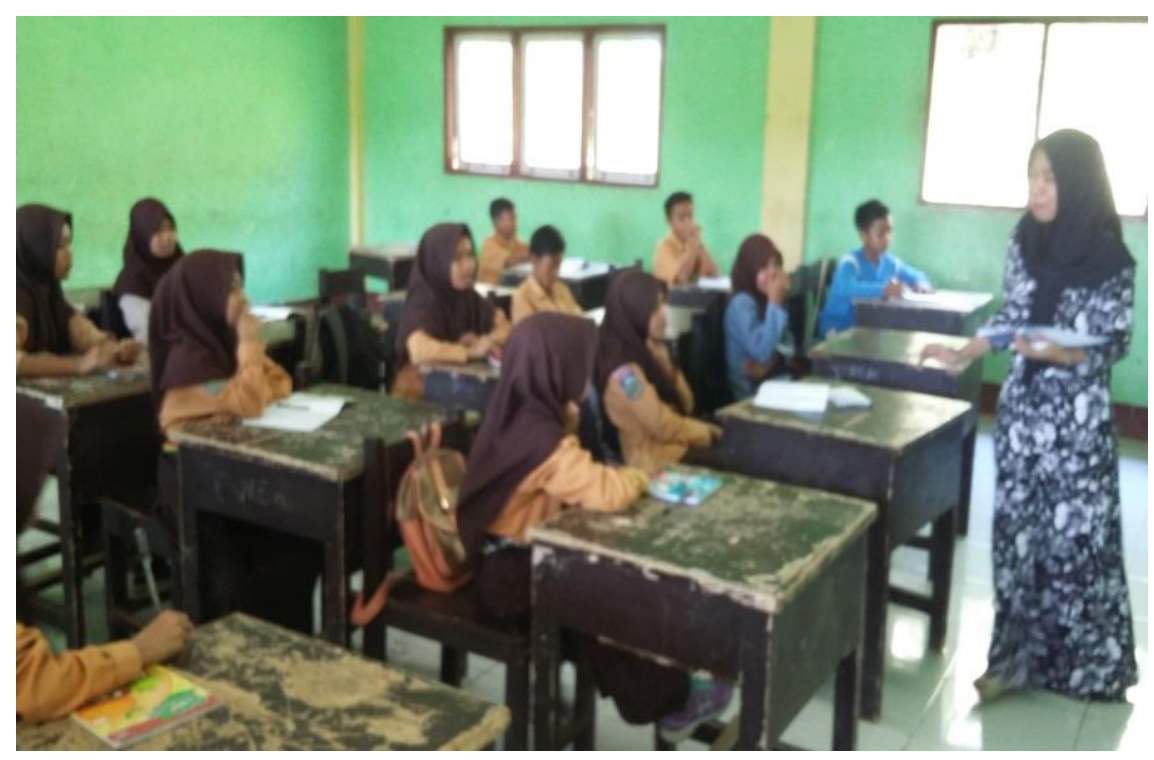

Gambar 3. Foto dokumentasi pengabdian 2

\section{Kesimpulan}

Pembelajaran dengan menggunakan Media Triple $P$ (Presentation, Practice, Production) dapat meningkatkan motivasi dan meningkatkan keterampilan bahasa Inggris siswa-siswi di SMPN 19 Mataram. Kegiatan kursus bahasa inggris yang diberikan kepada siswa-siswi tersebut memberikan dampak posistif bagi siswa-siswi tersebut. Kegiatan kursus ini sangat membantu siswa-siswi dalam meningkatkan pencapaian pelajaran Bahasa Inggris di Sekolah sehingga guru bisa terbantu dalam pencapaian pembelajaran tersebut. Kegiatan kursus bahasa inggris yang dilakukan di SMPN 19 Mataram Kec. Sandubaya, Kota Mataram, Nusa Tenggara Barat. Kegiatan di sekolah ini merupakan kegiatan yang positif yang bisa mendukung siswa dalam meningkatkan pembelajaran khususnya pada mata pelajaran bahasa Inggris.

\section{Ucapan Terimakasih}

Ucapan terima kasih yang tak terhingga diberikan kepada Universitas Bumigora selaku pelindung dalam kegiatan pengabdian ini. kami juga ucapkan terima kasih kepada Ketua LPPM beserta jajarannya yang telah memberikan dukungan dan bantuan dalam kegiatan ini sehingga pengabdian ini bisa berjalan dengan lancar. Tidak lupa pula kami sampaikan apresiasi kepada Kepala Sekolah SMPN 19 Mataram, guru dan staf-stafnya beserta anggota Karang Taruna desa Mambalan yang dengan senang hati untuk menerima dan meluangkan waktunya dalam mengikuti kegiatan ini. Pada akhirnya, kami berharap 
semoga kegiatan ini memberikan manfaat bagi para peserta kursus khususnya dan Sekolah SMPN 19 pada umumnya.

\section{Daftar Pustaka}

Batemen, J. R. M. and J. A. (1992). Review Article James R. Martin's English Text: System and structure John A. Bateman.

Harmer, J. (2004). The Practice of English Language Teaching.

Richards, J. C., \& Renandya, W. A. (2002). Methodology in Language Teaching.

Rodgers, T., Theodore, S., Jo, M., \& John, S. (1986). Approach and Methods in Language Teaching.

SMPN 19 Mataram. (2018). Www.Kemdikbud.Go.ld.

http://sekolah.data.kemdikbud.go.id/index.php/chome/profil/6089B7E4-023C-E111-AE1F730B95379F8E

Wiratno, T. (2018). Linguistik Sistemik Fungsional. Pustaka Pelajar. 
